Vol. 9,\#3, Diciembre 2005.

http: // revista-redes.rediris.es

\title{
Redes sociales personales y calidad de vida en personas desplazadas por violencia política: el caso de Barranquilla (Colombia) ${ }^{1}$
}

\author{
Jorge Enrique Palacio Sañudo, Universidad Del Norte- Colombia² \\ Camilo Alberto Madariaga Orozco, Universidad Del Norte- Colombia
}

\section{Resumen}

Se pretendía indagar la relación entre las redes sociales personales de los desplazados por violencia política y su calidad de vida en salud, lo cual podía modificarse con el tiempo de llegada al asentamiento - menos de tres meses y más de un año. Se esperaba observar si a mayor densidad en la red personal, se encontrarían bajos niveles en la calidad de vida de los desplazados, lo cual unido a otros factores sociales reduciría su sentido de comunidad y capacidad de adaptación. La muestra se tomó en Pinar del Río (periferia de Barranquilla - Colombia), con 19 personas seleccionadas por muestreo en bola de nieve ( 8 hombres, 11 mujeres con edades entre 27 y 61 años). Respondieron un cuestionario sobre Calidad de Vida en Salud (SF-36) (McHorney et al., 1994), y el Arizona Social Support Interview Schedule (ASSIS) de Barrera (1980, citado por Araya y Maya, 2005). Los resultados mostraron que no existen correlaciones significativas entre los que Llegan y los Asentados en las variables de estudio, pero se encontró evidencia que la calidad de vida en su dimensión de salud física, es menor en los desplazados que llevan más de un año en el asentamiento, con respecto a los que tienen menos de tres meses.

Palabras clave: Redes sociales. Calidad de Vida. Desplazados. Colombia.

\begin{abstract}
This article is based on a research that explored the relations between the Personal Social Network of people who have been displaced because of political violence and their Quality of Life in Health. These relations can be modified by the time of being in the new place of refuge - less than three months and more of one year. The hypothesis looked for if to greater density of the Personal Social Network of displaced people the Quality of Life in Health was low, which together with other social factors would reduce their Sense of community and capacity of adaptation. The data were collected in Pinar del Río (periphery of Barranquilla - Colombia), with 19 people selected in snow ball sample ( 8 men, 11 women, between 27 and 61 years). They responded to a questionnaire on Quality of Life in Health (Sf-36) (McHorney et al., 1994), and the Arizona Social Support Interview Schedule (ASSIS) of Barrera (1980, cited by Araya and Maya, 2005). The results do not show significant correlation between the time of refuge with the study variables, but it was observed that the Quality of Life, in its dimension of physic health, is smaller in displaced people with more of one year in the new place of refuge, with respect to displaced people who have less than three months in the new place of refuge.
\end{abstract}

Keywords: Social Network Analysis, Quality of Life, Displacement, Colombia.

\footnotetext{
${ }^{1}$ Investigacion presentada en el III Seminario para el Análisis de Redes Sociales en Sevilla - España. I International Workshop (7, 8 y 9 de Septiembre). Coordinadores Isidro Maya, Jose Luis Molina y Estrella Gualda. La investigación contó con el apoyo del Centro de Investigaciones en Desarrollo Humano (CIDHUM), así como del Dr. Rafael Tuesca y las estudiantes de psicología Roxana Arenas y Alejandra Polo de la Univesidad del Norte.

2 Profesores del Programa de Psicología de la Universidad del Norte, Barranquilla - Colombia. Correspondencia: jpalacio@uninorte.edu.co; cmadaria@uninorte.edu.co
} 


\section{Desplazamiento y reconstrucción de comunidad}

En el mundo existen 52 países en los cuales se encuentran aproximadamente unos 25 millones de personas que se han movilizado en su interior (desplazados internos) para salvar sus vidas por los desastres ambientales o por los conflictos o violaciones de los Derechos humanos que han sufrido en su país o región (ver Figura 1$)^{3}$. También se encuentran los desplazados externos o emigrantes que son aquellos que han logrado salir del país en conflicto, pero a pesar de ser sólo la mitad de los internos reciben mayor atención humanitaria por su calidad de refugiados (Estatuto de Refugiados de 1967 por parte de la ONU) ${ }^{4}$. Colombia, no es ajena a esta problemática, ya que la violencia interna vivida en los últimos veinte años ha generado un acumulado aproximado de tres millones de personas desplazadas internamente y externamente en las modalidades de desplazamientos masivos o individuales (Red de Solidaridad Social, 2005).

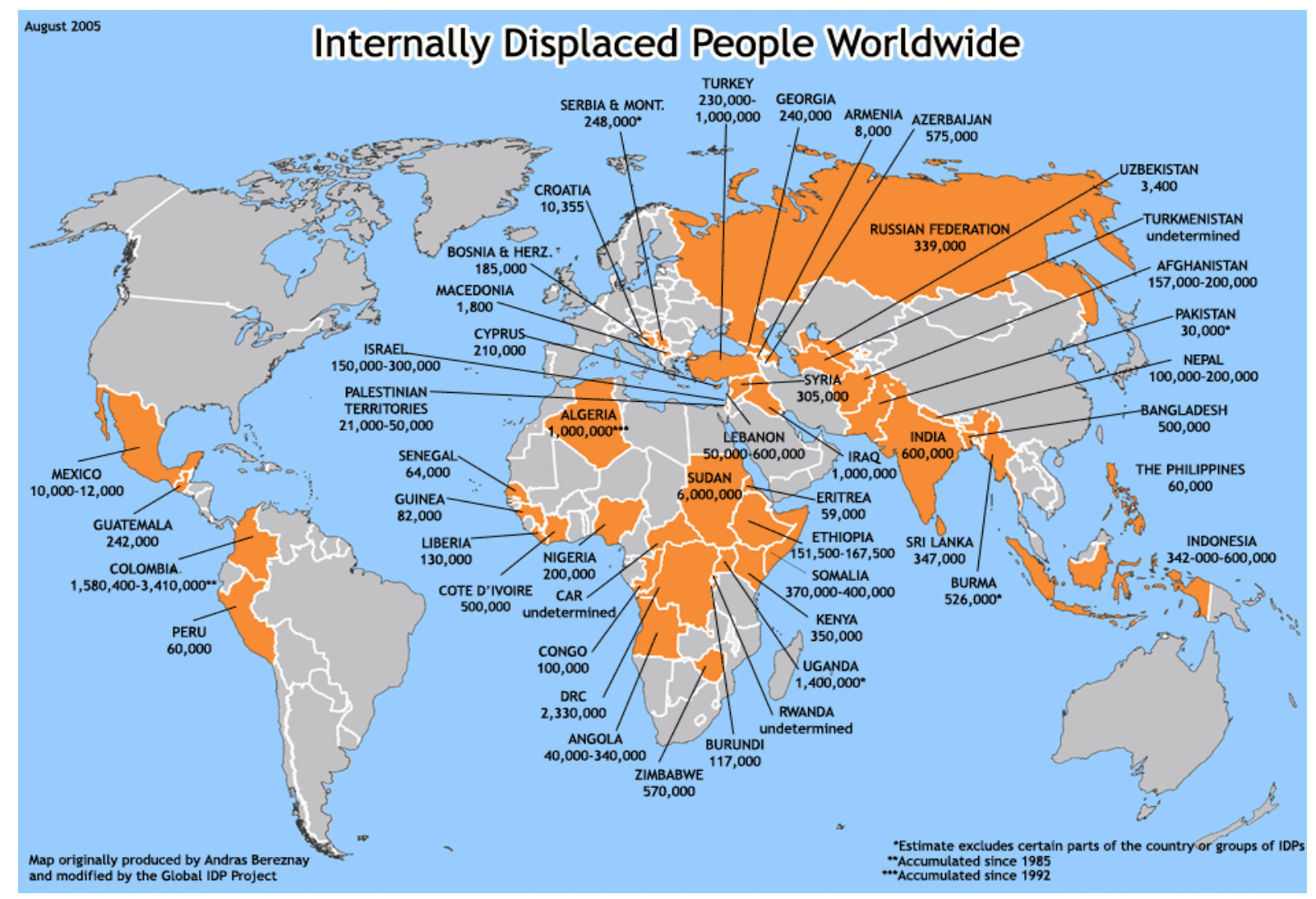

Tomado en junio 2005 de: http://www.idpproject.org/images/website_maps/IDP_worldmap.gif)

Figura 1. Cifras de desplazados internos a nivel mundial

\footnotetext{
3 Internal Displacement Monitoring Centre (IDMC) http://www.internal-displacement.org/

${ }^{4}$ http://www.acnur.org/biblioteca/pdf/0003.pdf
} 
Son diversas las causas que generan este desplazamiento en Colombia, y se puede expresar entre algunas de ellas las desmovilizaciones de los grupos armados ilegales, la intensificación del conflicto entre el estado y estos grupos, la estrategia de guerra de apropiarse de zonas estratégicas por su importancia económica o de tránsito para diversos tipos de comercio, las fumigaciones de cultivos ilícitos, los confinamientos o bloqueos de las comunidades campesinas que les generan dificultades para acceder a la alimentación o sacar sus productos, así como las dificultades de integración social de personas o grupos desplazados que no logran reconstruir sus historias de vida al lado de otros grupos receptores (CODHES, 2004).

La dificultad de integración de los desplazados se entiende mejor en la medida que se observa la manera en que llegan a las comunidades receptoras. Ellos se instalan generalmente en los barrios situados en la periferia de las grandes ciudades o de las cabeceras municipales, donde se suman a las familias pobres instaladas desde tiempo atrás. Estas familias crean nuevos barrios tuguriales y se convierten en una carga para la población que las recibe (Salazar, 1995). En la interacción de ambos grupos (desplazados o que llegan y receptores o asentados) se construye el contexto en el que se dará la adaptación temporal o definitiva al nuevo ambiente de vida para todos en la comunidad.

Sin embargo, este contacto entre colombianos de diferentes regiones está modulado por factores personales, sociales y ambientales que tienen que ver con múltiples aspectos que se articulan generalmente en su contra: para la persona o familia que llega desplazada se puede mencionar la manera en que están afrontando los impactos de la violencia de manera individual y como núcleo familiar (Palacio y Sabatier, 2002); para los asentados, que pueden ser antiguos desplazados o personas autóctonas de la comunidad, se debe observar los estereotipos y temores que abrigan sobre los recién llegados (ej. regionalismos, estereotipos negativos, temores sobre la disminución del acceso al trabajo, el aumento de la inseguridad, etc.,..), y en general toda idea que ambos grupos traen por su cuenta y que se reforzará posteriormente en la interacción de ambas comunidades (receptora - desplazada).

La política gubernamental incentiva el retorno de los desplazados pero esto no es posible en muchos casos en la medida que los conflictos persisten en las regiones de las cuales proceden, así que una de las opciones más adecuadas de intervención es procurar favorecer la adaptación temporal o definitiva de estas familias a su nuevo lugar de vida mediante la construcción de "Comunidad" entre desplazados y 
receptores como una manera de apoyarse mutuamente en la búsqueda de alternativas viables a sus problemáticas sociales.

La generación de Sentido de Comunidad es una condición fundamental para garantizar el éxito de cualquier estrategia de adaptación definida por el gobierno o los organismos no gubernamentales de apoyo, en la medida que independientemente que los desplazados retornen o se asienten en otras regiones o se regresen a su propio pueblo, lo fundamental es que cada uno de ellos o en su núcleo familiar, pueda al cabo de cierto tiempo de adaptación5 percibirse cada vez más cercano a los otros que hacen parte de su mismo barrio o comunidad, además que identifiquen su interdependencia con sus vecinos y la voluntad de mantener este vínculo realizando comportamientos de apoyo o prosociales de manera recíproca (Sarason, 1974, citado por Maya, 2004). En general, se esperaría que los desplazados y los receptores logren a la larga sentirse parte de una comunidad más amplia, que les brinde estabilidad y confianza, tal como es el "deber ser" de la nación y sus instituciones, y en últimas que el clivaje desplazados/receptores desaparezca.

\section{La Construcción de comunidad frente a bajos niveles de calidad de vida}

Una de las dificultades en la construcción de Sentido de Comunidad es la situación de extrema pobreza que enfrentan los desplazados y la población receptora. Aquí se pueden apreciar diversas situaciones de carencia que repercuten en su calidad de vida la cual se define como la combinación de las condiciones de vida objetivas y la satisfacción subjetiva ponderadas por la escala de valores, aspiraciones y expectativas personales (Felce-Perry 1995, Gómez-Vela y Sabeh, 2005; BorthwickDuffy, 1992). Desde la mirada de las condiciones objetivas, se observa que el acceso a fuentes nutritivas de alimento se reduce a los tres primeros meses durante los cuales se les brinda asistencia humanitaria por parte del estado, y luego esta situación empeora considerablemente al verse librados a ellos mismos o a la ayuda intermitente de las ONG's. Por otro lado, las viviendas o espacios de vida se construyen generalmente con materiales de desecho y no cuentan con ningún servicio sanitario (PMA, 2003).

\footnotetext{
${ }^{5}$ Por la magnitud de la desestructuracion del nucleo familiar y de las comunidades en general puede hablarse hasta de dos generaciones que deberán pasar - siendo optimista - para tratar de retormar nuevamente un rumbo más equilibrado de desarrollo individual y social. Esto implica que es necesario desde ya pensar en el restablecimiento postconflicto.
} 
También se observa con respecto a su salud que la situación no es la mejor. En el 2002, sólo el 22\% de esta población recibía atención médica (Marie Stopes International, 2003), y no asistían por falta de dinero o por falta de los documentos de identificación, a pesar que por ley es una obligación de los Hospitales atender a esta población. En general, en el 2003 el índice de mortalidad en esta población era 6 veces mayor que el promedio nacional (PMA, 2003). En los dos últimos años el aporte económico del gobierno para atender las necesidades de esta población ha aumentado considerablemente, al igual que los subsidios para educación, sin embargo frente a la magnitud de sus problemáticas sigue siendo necesario incrementarlo.

Desde la mirada de la satisfacción subjetiva en las variables de la calidad de vida, se debe observar las particularidades en el afrontamiento de esta situación por parte de las personas o los grupos de familias, lo cual influye enormemente en su bienestar psicológico percibido. Las familias desplazadas que provienen en su mayoría de ámbitos rurales se encuentran, generalmente, fragmentadas por la pérdida de uno o varios de sus miembros. Están conformadas en su mayoría por la madre, quien debe asumir el papel de jefe de hogar, y los hijos. Esta composición, por estar sustentada en rupturas a causa de la violencia, se convierte en un ámbito propicio para la acentuación de la misma, tanto en su interior como en la comunidad en la cual se encuentran asentados (CODHES, 1997; Rueda, 1997).

Además, la pérdida de los seres queridos, el abandono de la tierra, y la salida de su región producen en las personas diversos sentimientos de impotencia, tristeza, ansiedad y depresión (Palacio, Abello, Madariaga, Sabatier, 1999), que corren el riesgo de convertirse en comportamientos hostiles hacia ellos mismos o hacia su entorno. Si añadimos a esto las dificultades de adaptación social debido a los conflictos con los residentes (por los estereotipos y temores entre ambas comunidades mencionados anteriormente), nos damos cuenta la presión psicológica que sufre esta población, y la magnitud aún oculta de su problemática. Lo que es también inquietante, es la posible reproducción del ciclo de la violencia como respuesta a todas estas situaciones de carencia y sufrimiento vividas por los niños y jóvenes (Castaño, 1994).

Frente a esta situación tan compleja es válido preguntarse, ¿cómo se puede generar confianza y Sentido de Comunidad? ¿Cómo se organizan y funcionan las redes de apoyo en medio de la desconfianza? ¿Pueden estas redes de apoyo mejorar la calidad de vida en estos contextos difíciles? De hecho, la confianza en medio de la carencia, la desesperanza y los demás sentimientos encontrados por la 
expulsión o huida de sus lugares de origen crean condiciones de vida que generan en su lugar desconfianza, resentimiento y prevención hacia los otros. No hay duda que los desplazados al llegar a los sitios de asentamiento siguen expuestos a la violencia y a otras violaciones de sus derechos humanos que si bien no son tan visiblemente contundentes como la exposición al conflicto armado directo, sí generan un acceso muy limitado al alimento, empleo, educación y tratamiento médico que los lleva de manera acelerada a condiciones de vida que pueden dejar huellas aún más difíciles de borrar.

\section{Redes en medio de la desconfianza}

El cambio o disgregación de las redes sociales de las personas o de la familia por el proceso del desplazamiento se convierte en una fuente de estrés que se suma a las situaciones de por sí traumáticas de la movilidad geográfica y social (Vega, Kolody, Valle y Weir, 1991, Castaño, 1994). Como se mencionó anteriormente se observa en primer lugar la degradación de su calidad de vida por la pérdida de sus bienes y del estilo de vida cotidiano (Osorio y Lozano, 1995), y posteriormente se observa una discriminación de esta población por parte de diferentes personas de la sociedad civil que podrían prestar algún tipo de apoyo. Esta situación ha cambiado algo en la medida que se ha despertado un mayor sentido de solidaridad reforzado por varias campañas publicitarias desde los inicios del 2003 por parte del gobierno para incentivar el sentimiento de solidaridad hacia los desplazados, y para hacer valer el derecho a la asistencia medica en diferentes instituciones de salud.

Con relación al soporte recibido por estas familias de parte de la sociedad en general, se encuentra que en 1994-1995, un 42,4\% de los hogares desplazados no habían recibido un tipo de ayuda específica. Los que recibieron ayuda, la obtuvieron de los amigos y de la familia (próxima y lejana). Otros recibieron ayuda de la iglesia, de organismos comunitarios, de las ONG (5\%) y de diferentes organismos del Estado (6,5\%), los cuales dieron una ayuda alimentaria, alojamiento, servicios de salud, de educación, asesoria jurídica o incluso soporte moral (Osorio y Lozano, 1995). Para los mismos autores, un $26,6 \%$ de las mujeres se ven obligadas a convertirse en jefe de familia (por viudez o separación) y entran al mismo tiempo en la economía informal (vendedores ambulantes, servicios domésticos, celadores, etc.). En la actualidad esta situación es en general similar sólo que el estado participa más en la ayuda a esta población, la cual también continúa recibiendo aportes de algunas ong's que se vuelven esporádicos o intermitentes y no tienen el impacto esperado en la generación de dinámicas de organización comunitaria a excepción de ciertas experiencias particulares llevadas a cabo en comunidades 
campesinas o indígenas. Además, otras problemáticas sociales se han hecho visibles o se han incrementado en estas comunidades, entre las cuales se encuentran la violencia intrafamiliar, el abuso sexual de menores, la prostitución infantil, la delincuencia juvenil así como el consumo y expendio de sustancias psicoactivas.

\section{Lazos débiles Vs lazos fuertes}

Con respecto a la construcción de redes y la salud mental de los desplazados, en un estudio de Palacio y Sabatier (2002), se observaron las redes de 49 familias desplazadas y 50 no desplazadas de un sector de la periferia de Barranquilla (norte de Colombia) y se relacionaron con las características de salud mental de los jóvenes que vivían con ellos. Para observar las redes se utilizó un cuestionario de José Gimon, adaptado por Madariaga, Martinez, Vides (1993), donde se indagaban los tipos de apoyo recibido y quién los daba. Para la salud mental se utilizó el cuestionario de Macksoud, Aber, Dyregrov, Raundalen (1990), que mostraba indicadores de depresión, ansiedad, agresividad, así como de comportamientos prosociales y de planificación.

Los resultados indicaron que en general las familias desplazadas presentaban un mayor número de miembros en sus hogares en comparación con las familias no desplazadas, así como más interacciones con los familiares que viven en el barrio, lo cual implica también un número mayor de miembros en sus redes de amigos y familiares. Por otro lado sus redes están conformadas por núcleos más densos de miembros (10 a 13 miembros), mientras que los no desplazados tienen menos miembros en sus redes ( 3 a 8 miembros) y su frecuencia de intercambios con los amigos era más elevada. Los no desplazados dicen recibir un mayor apoyo afectivo por parte de la madre, mientras que los desplazados indicaron recibirlo por parte de los vecinos. En las situaciones difíciles, todas las familias recurren a las personas que viven en el barrio, pero los desplazados recurren principalmente a la familia nuclear, mientras que los no desplazados recurren también a la familia extensa, mostrando estos últimos mayor versatilidad para obtener ayuda.

Con respecto a la relación de estos indicadores con la salud de los jóvenes, se observó que en todas las condiciones, el número elevado de miembros en la red de los padres (densidad) se relacionaba con índices elevados de depresión en los jóvenes. También se observó que a medida que aumentaba el tiempo de haber llegado al pueblo en la familia desplazada disminuían el número de miembros en su 
red (densidad), y sus interacciones, llegando a un nivel similar al de las familias no desplazadas.

La estructura y funcionalidad de la red de apoyo que se refleja en este estudio puede tratar de entenderse mejor desde la teoría de los lazos débiles de Granovetter (1973), la cual menciona - a grosso modo - que se tiene más acceso a los recursos del medio a través de los conocidos (lazos débiles) que a través de los familiares y amigos íntimos (lazos fuertes). Además, los lazos fuertes implican mayor número de relaciones, mayor cercanía, más personas y por lo tanto una alta densidad, mientras que los débiles reflejarían pocas relaciones, mayor distancia, pocas personas y poca densidad. La ventaja de los lazos débiles radica en que los conocidos tienen a su vez amigos íntimos que pueden abrir el acceso a otras redes e informaciones potencialmente importantes para la vida social de una persona o grupo determinado. Esto convierte a la mayoría de los lazos débiles no en una "debilidad" sino en "puentes" entre dos o más redes de amigos íntimos que proporcionan acceso a información y recursos que están más allá del círculo íntimo6. De allí que los lazos débiles disminuyen la fragmentación de las redes sociales a su vez que le dan más consistencia, y fomentan la ocurrencia de eventos cohesivos. Los lazos fuertes - en cambio - proporcionarían más ayuda y estarían más disponibles o accesibles.

Sin embargo esta teoría se debe matizar en contextos de pobreza, tal como ocurre en la población desplazada. Granovetter (2003), indica que en los grupos socioeconómicos bajos (con alta inseguridad económica y falta de servicios sociales), los lazos débiles a menudo no son puentes, sino que representan a conocidos de amigos o parientes que están inmersos en la misma problemática de carencia, de allí que la información que proporcionan no constituye un aumento real de oportunidades para mejorar los ingresos económicos. En los grupos socioeconómicos altos los lazos débiles sí tienden un puente sobre la distancia social, de manera que si no hay oportunidades visibles en el círculo íntimo, las personas pueden recurrir a los conocidos de otros círculos, conllevando un efecto positivo para el ingreso económico. Además otros estudios como el de Lin, Ensel y Vaughn (1981, citado por Granovetter, 2003), indican que los lazos débiles actúan mejor si estas relaciones débiles se establece con personas de mayor estatus, lo cual no es el caso mejor representado en la población desplazada.

\footnotetext{
${ }^{6}$ Sin embargo todos los lazos débiles no construyen puentes.
} 
Como se observa, los lazos débiles no son muy útiles en condiciones de pobreza, y además se encuentran evidencias que los pobres confían más en los lazos fuertes para acceder a diferentes recursos. Esto se presenta en el estudio de Ericksen y Yancey (1977, citado por Granovetter, 2003), llevado a cabo en Filadelfia con población joven, de raza negra y con bajo nivel de instrucción, al igual que en otros estudios donde las personas de bajos recursos recurren sobre todo a los lazos fuertes en contextos culturales muy diferentes (Stack, 1974 y Lomnitz, 1977, citados por Granovetter, 2003). El estudio de Blau (1974), indica además que cuanto más bajo es el estrato de clase de una persona, mayor será la frecuencia relativa de los lazos fuertes. Esto puede apoyar lo encontrado en los desplazados quienes recurren en mayor medida a la familia nuclear (lazos fuertes) para solicitar apoyo en situaciones difíciles, mientras que los no desplazados recurren a la familia extensa. Lo interesante es observar cómo a medida que pasa el tiempo en el asentamiento las relaciones de los desplazados disminuyen, es decir que la estructura de la red se reconfigura de acuerdo a parámetros que se relacionarían con criterios para acceder mejor a los recursos.

\section{Lazos y salud mental}

Como se observó en el estudio de Palacio y Sabatier (2002), a mayor tiempo de haber llegado al asentamiento y mayor densidad en las redes de las familias, los indicadores de salud mental de los jóvenes empeoraron. Estos resultados en general no están de acuerdo con lo esperado de una red en el contexto de la salud, en el cual se estima que frente a redes densas lo más efectivo en ellas sería el mayor soporte social que brindan a las personas que están en su interior. Esto funcionaría debido a que uno de los principales efectos de intercambio con el medio se produce en el plano de la identidad y la autoestima, que son elementos centrales en la adquisición y mantenimiento de la salud mental. La red aseguraría un mejor soporte emotivo, y permitiría utilizar - de una manera más adecuada - las estrategias de adaptación, aumentando también la actividad de la persona y provocando toda una gama de emociones que tendrían un efecto sobre el sistema inmunitario (Tousignant, 1992).

Sin embargo es necesario tener en cuenta que al aumentar la cantidad de relaciones sociales la probabilidad de sufrir estrés interpersonal también aumenta (Cohen y col., 1985, citado por Eurelings-Bontekoe y col., 1995), y éste puede ser el caso para la población desplazada. Además en esa investigación se evidencia que la red de las familias desplazadas era más numerosa pero los intercambios se 
orientaban más a elementos materiales o en especie, mientras que las familias no desplazadas presentaban redes más pequeñas y con mayor intercambio afectivo, lo cual incrementaría la calidad en las relaciones de estos últimos. Sobre esto Barrera y Sandler (1980), indican que el elemento que influye en la salud mental no es sólo el apoyo social sino la calidad de éste y la satisfacción que procura, por lo cual los desplazados tendrían una red densa pero de poca calidad afectiva, lo cual entra a ser un factor determinante en su efectividad por las características psicosociales propias de esta población.

Estos datos aún contradictorios o que muestran el delicado equilibrio que implica la red, el apoyo social y la densidad, permiten identificar algunos efectos paradójicos mencionados por Leavy (1983, citado por Tousignant 1992), en relación con los estilos de personalidad y la manera de percibir el apoyo brindado por el medio, pero en general existe suficiente evidencia empírica para que se pueda hablar de un vínculo significativo entre la ausencia de apoyo social y la presencia de problemas psicológicos, a pesar que los elementos de unión no están claramente definidos.

De aquí surgen múltiples cuestionamientos sobre el modelo de red y el apoyo social en este tipo de situaciones, pero un primer interrogante que se ha seleccionado como una manera de ampliar la información sobre las redes sociales y la salud de esta población es el siguiente: ¿Qué relación existe entre los indicadores de redes sociales personales de los desplazados y sus indicadores de calidad de vida en salud? Además, se agregó la variable "tiempo de llegada", la cual se considera pertinente para continuar en la línea de los resultados del estudio de Palacio y Sabatier (2002). De esta manera se abordó la red y los indicadores de calidad de vida de un grupo de personas que tienen diferentes tiempos de vivir en una misma población receptora (menos de tres meses - Llegan, y más de un año - Asentados).

Se establecieron dos hipótesis de trabajo: la primera hipótesis tenía que ver con el tiempo: se esperaba que los indicadores de calidad de vida y de redes sociales fueran significativamente diferentes en los dos grupos de desplazados. La segunda hipótesis se dirigía a observar si los altos niveles de densidad en la red social personal se relacionarían con bajos niveles de calidad de vida. Para tratar de probar estas hipótesis, se organizó la siguiente estructura metodológica, que sólo pretende sentar las bases para estudios posteriores con poblaciones más numerosas y que asume las limitaciones del muestreo que se presenta a continuación. 


\section{Metodología}

Sujetos

El estudio se llevó a cabo en Pinar del Río, el cual es un asentamiento que tiene unos 7 años de haber sido fundado y avalado por el gobierno. Se encuentra en la periferia noreste de Barranquilla y cuenta aproximadamente con 450 familias que han llegado desplazadas por violencia política de diferentes regiones del país. Se seleccionaron 19 personas ( 8 hombres y 11 mujeres con edades entre 27 y 61 años) por medio de un muestreo en bola de nieve - en la medida que la población hay desplazados y no desplazados y no es fácil distinguirlos. El contacto se realizó gracias a un líder comunitario quien ayudó a localizar las primeras familias en el asentamiento. El criterio de selección se relacionaba exclusivamente con entrevistar adultos de ambos sexos y diferentes familias con un tiempo variable de haber llegado al asentamiento (menos de tres meses y más de un año). Las características de los sujetos que participaron en el estudio se presentan en la Tabla 1.

\begin{tabular}{|c|c|c|c|c|c|c|}
\hline \multicolumn{2}{|c|}{} & \multicolumn{2}{c|}{ Llegan } & \multicolumn{2}{c|}{ Asentados } & \multirow{2}{*}{ Total } \\
\cline { 3 - 6 } & Masculino & Femenino & Masculino & Femenino & \\
\hline \multirow{2}{*}{ Edad } & De 27 a 38 años & 1 & 4 & 2 & 2 & 9 \\
\cline { 2 - 6 } & De 39 a 61 años & 2 & 3 & 3 & 2 & 10 \\
\hline \multicolumn{2}{|c|}{ Total } & 3 & 7 & 5 & 4 & 19 \\
\hline
\end{tabular}

Tabla 1. Frecuencia Edad* Sexo* Tipo de desplazados

\section{Instrumentos}

Se utilizaron dos instrumentos que se adaptaron previamente en un estudio piloto con cinco sujetos de la comunidad. El primer instrumento es un cuestionario sobre Calidad de Vida en Salud (SF-367), el cual puede ser auto administrado, pero en éste se realizó una entrevista personal. Está recomendado para ser utilizado tanto en población general como en personas con una edad mínima de 14 años. El SF-36 se puntúa de forma que una puntuación mayor indica un mejor estado de salud (Iraurgi, Póo, Màrkez, 2004). El cuestionario de 36 ítems forma 8 dimensiones que evalúan la calidad de vida percibida en salud física y psicológica (Función Física, Rol físico, Dolor corporal, Salud General, Vitalidad, Función Social, Rol Emocional y Salud mental). La consistencia interna (Alfa) fue de 0,71.8

\footnotetext{
${ }^{7}$ Ver http://www.sf-36.com

${ }^{8}$ Se eliminó el item $11 d$.
} 
El segundo instrumento es un cuestionario sobre redes sociales que permite generar los nombres de las personas que hacen parte de la red social personal e identificar los tipos de apoyo percibido (Arizona Social Support Interview Schedule - ASSIS - Barrera, 1980, citado por Maya y Araya, 2005). Luego de preguntar sobre la Calidad de Vida, se continuaba indagando sobre el apoyo recibido para tratar asuntos personales, solicitar dinero, consejo, retroalimentación positiva, ayuda instrumental y compartir el tiempo libre. Los entrevistados debían mencionar todos los nombres que sea posible $(5,10$ o más) de los proveedores de apoyo, y luego completar hasta donde quisieran una lista con los nombres de las personas que consideraban significativas en el lugar dónde vivían de acuerdo a la calidad y el tipo de apoyo brindado, indicando además qué tanto se conocían entre ellos.

\section{Procedimiento}

Luego de realizar las entrevistas semiestructuradas para recoger los datos de Calidad de Vida y Redes Sociales, se procedió a construir una base de datos en UCINET (Borgatti, Everett y Freeman, 2002), el cual permitió obtener los indicadores estructurales de la red (densidad, centralidad, centralización, intermediación, cercanía), y los grafos de cada grupo de sujetos en estudio. Luego en SPSS se procesaron los datos del cuestionario de Calidad de Vida y se obtuvieron las distribuciones de cada una de sus escalas. Posteriormente se compararon mediante la $\mathrm{t}$ de student los promedios de Redes y Calidad de Vida entre el grupo de Asentados con el grupo que Llega, y finalmente se realizó una correlación de Pearson para identificar la relación entre los indicadores de redes y de calidad de vida.

\section{Resultados}

Los resultados se presentarán describiendo brevemente cada una de las variables por separado y las comparaciones entre los grupos de desplazados que Llegan y los Asentados. Por último se mostrarán las relaciones entre ellas.

\section{Calidad de vida y tiempo de llegada}

Los Indicadores de Calidad de Vida (Salud Física y Mental) en los sujetos que Llegan y los Asentados presentan resultados que confirman las difíciles condiciones de vida que experimenta esta población (Ver Figura 2). Los niveles promedio de todas las subescalas están entre 31 y 55 puntos, cuando en la población española normal el promedio general es de 77 puntos con una desviación estándar muy reducida (Iraurgi, Póo, Màrkez, 2004). 


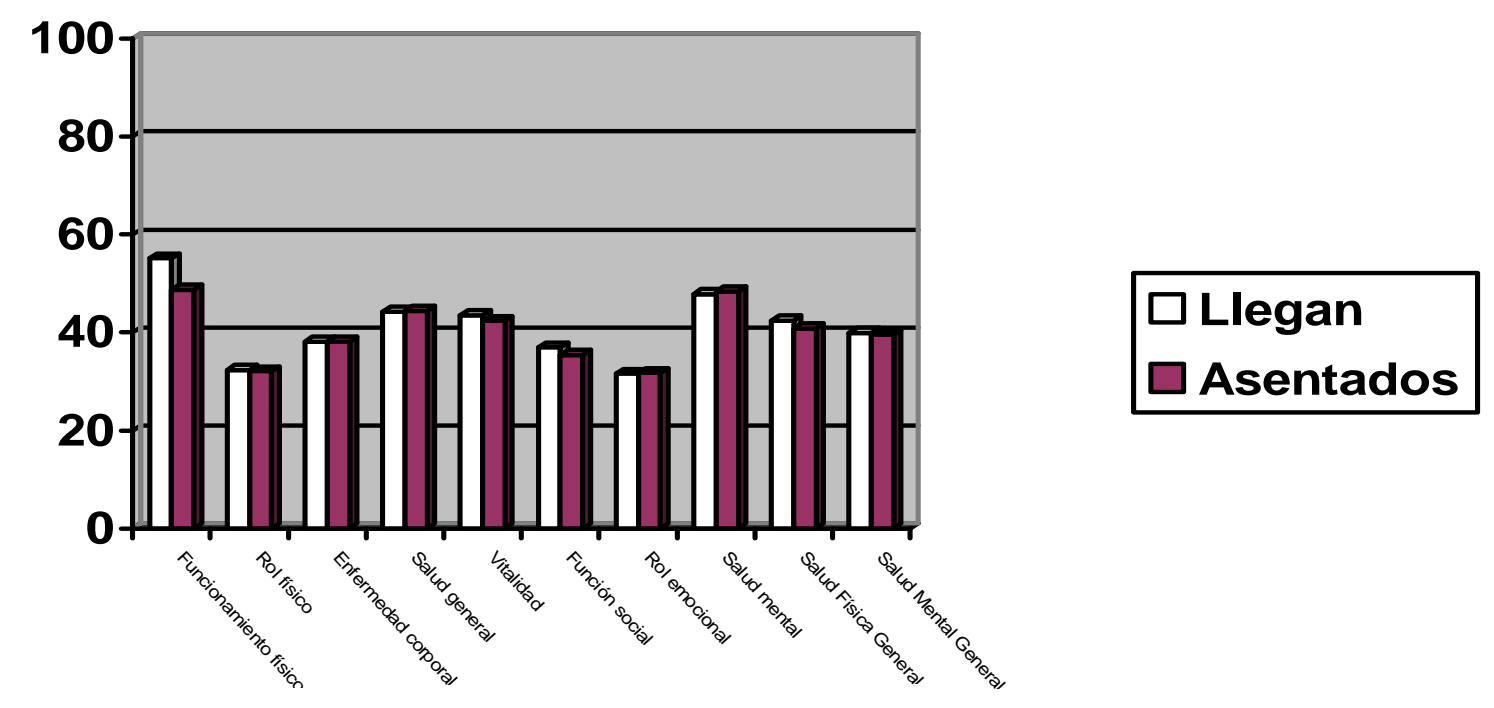

Figura 2. Subescalas de la calidad de vida de acuerdo al grupo de desplazados

Es preocupante que sólo logran un nivel de 50 puntos los desplazados que Llegan, y lo hacen en la subescala de funcionamiento físico, indicando que su salud en general no los limita en exceso para realizar las actividades físicas como el cuidado personal, andar, subir escaleras, inclinarse, coger o cargar peso y los esfuerzos moderados e intensos. Sin embargo, en la dimensión física sí sienten una gran limitación en lo que tiene que ver con su rol físico, es decir que consideran que no pueden desempeñar adecuadamente un trabajo y otras actividades diarias por presentar limitaciones en su desempeño ocasionadas por molestias de salud. Desde la dimensión de salud mental, se observa que el rol emocional presenta las puntuaciones más bajas. Esto sugiere que los desplazados sin importar el tiempo de llegada al asentamiento consideran que los problemas emocionales interfieren en su trabajo o en otras actividades diarias.

Con respecto al tiempo de llegada al asentamiento, se tiene que los promedios de calidad de vida son muy parejos en ambos grupos, pero se observa que los que tienen más de un año (Asentados) presentan los niveles de calidad de vida más bajos, y esta diferencia se hace significativa en las subescalas de Funcionamiento físico y Vitalidad (mayor sentimiento de cansancio), indicando que su Salud física general está más deteriorada en comparación con aquéllos que tienen menos de tres meses de haber llegado (Ver Tabla 2). Estos datos confirmarían al menos parcialmente la primera hipótesis con respecto a la variable tiempo y calidad de vida en salud, y están en la misma dirección que lo encontrado por Palacio y Sabatier (2002). 


\begin{tabular}{|c|c|c|c|c|c|}
\hline \multirow{3}{*}{$\begin{array}{l}\text { Indicadores de Calidad } \\
\text { de Vida }\end{array}$} & \multicolumn{4}{|c|}{ Grupo de desplazados } & \multirow{3}{*}{ Valor $\mathbf{t}$} \\
\hline & \multicolumn{2}{|c|}{ Llegan } & \multicolumn{2}{|c|}{ Asentados } & \\
\hline & Promedio & DE* & Promedio & DE & \\
\hline Funcionamiento físico & 55,10 & 4,25 & 48,78 & 3,27 & $3,59 * *$ \\
\hline Rol físico & 32,40 & 1,57 & 32,11 & 33 & 0,53 \\
\hline Enfermedad corporal & 38,10 & 1,52 & 38,11 & 2,14 & $-0,01$ \\
\hline Salud general & 44,20 & 1,13 & 44,44 & 2,92 & $-0,24$ \\
\hline Vitalidad & 43,50 & 1,35 & 42,33 & ,70 & $2,31 * *$ \\
\hline Función social & 37 & 1,82 & 35,44 & 1,59 & 1,97 \\
\hline Rol emocional & 31,60 & 1,17 & 31,78 & 97 & $-0,35$ \\
\hline Salud mental & 47,80 & 1,81 & 48,44 &, 52 & $-1,02$ \\
\hline Salud Física General & 42,45 & 1,56 & 40,86 & 1,45 & $2,28 * *$ \\
\hline Salud Mental General & 39,98 & 60 & 39,50 & 39 & 1,99 \\
\hline
\end{tabular}

* Desviación Estándar ** Diferencia significativa a 0,002 y 0,03

Tabla 2. Diferencias en la calidad de vida de los desplazados

\section{Redes sociales personales y tiempo de llegada}

Una revisión de los grafos (Ver en anexo la Figura 3 y 4), y de la estructura de la red personal de los desplazados que Llegan y los Asentados permite identificar que ambos grupos presentan estructuras relacionadas con redes personales pequeñas, las cuales tienen entre 4 y 14 integrantes, siendo el promedio de 7 personas por red, en las cuales las mujeres son mayoría ( 75 mujeres, 62 hombres). Las figuras que representan vínculos débiles (vecinos o conocidos) son prácticamente equivalentes en ambas poblaciones, y representan la minoría de los nodos marcados como familiares o amigos (15 nodos contra 122 de familiares o amigos). Sólo en el grupo de Asentados se observa cómo dos nodos de personas conocidas sirven de puente entre las redes personales de dos Egos, y de un total de 19 sujetos, sólo 8 de ellos consideran importante mencionar a personas conocidas en su red. Con respecto a la cantidad de apoyo, es interesante observar cómo en el grupo de los que Llegan, los pocos conocidos se presentan como actores principales en brindar una gran cantidad de apoyo, mientras que en el grupo de los Asentados el apoyo de los conocidos está mucho más mitigado.

La estructura de ambas redes (Asentados/Llegan), no presenta diferencias significativas en los indicadores de redes (Ver Tabla 3), lo cual indica que el tiempo no parece afectar - en esta muestra - la red social personal. Con estos resultados se descarta de manera parcial la primera hipótesis presentada, en la cual se esperaba encontrar diferencias significativas en las redes de estos dos grupos, y sólo se han encontrado algunas diferencias en la Calidad de Vida. La estructura se 
caracteriza por presentar en ambas redes lazos fuertes, donde los nodos son principalmente transmisores con relaciones mutuas, y se presentan altos niveles de cohesión por un contacto diario entre los miembros. Este contacto es asegurado en su mayoría por miembros de la familia próxima que viven en la misma casa del Ego o en sus inmediaciones cercanas, de allí que el tipo de recursos solicitados a esta red son de todo tipo (afectivos, económicos, informativos, de recreación, de socialización, etc.), y su grado de reciprocidad es elevado.

\begin{tabular}{|l|r|r||r|r|r|}
\hline \multirow{2}{*}{\begin{tabular}{c}
\multirow{2}{*}{$\begin{array}{c}\text { Indicadores de Redes } \\
\text { Sociales }\end{array}$} \\
\cline { 2 - 5 }
\end{tabular}} & \multicolumn{2}{|c|}{ Llegan } & \multicolumn{2}{|c|}{ Asentados } & \multirow{2}{*}{ Valor t** } \\
\cline { 2 - 5 } & Promedio & \multicolumn{1}{|c|}{ DE* } & \multicolumn{1}{|c|}{ Promedio } & \multicolumn{1}{c|}{ DE } & \\
\hline Densidad promedio & 1,66 &, 31 & 1,47 & 13,32 & 1,38 \\
\hline Centralidad promedio & 83,33 & 15,57 & 74,40 & 14,59 & 1,28 \\
\hline Cercanía promedio \% & 94,14 & 8,89 & 91,41 & 9,25 & 0,65 \\
\hline Centralización OutD \% & 15,30 & 15,67 & 20,52 & 12,59 & $-0,79$ \\
\hline Centralización I nD \% & 14,10 & 15,56 & 21,57 & 12,12 & $-1,15$ \\
\hline
\end{tabular}

* Desviación Estándar ** No hay diferencias significativas

Tabla 3. Diferencias en los indicadores de redes sociales personales de los desplazados

\section{Relaciones entre redes sociales y calidad de vida}

La segunda hipótesis se orientaba a establecer las relaciones entre los indicadores de redes y calidad de vida en ambos grupos. Los resultados indican que en los sujetos de esta investigación, no se observan relaciones significativas entre estas dos variables, por lo cual se descarta esta hipótesis (Ver en anexo la zona sombreada de las Tablas 4 y 5 ). Al observar las relaciones significativas entre las otras variables, se encuentra que en todos los grupos, la cercanía o proximidad correlaciona negativamente con la centralización y la intermediación. Es decir que a medida que la proximidad aumenta entre los nodos, las distancias entre ellos disminuyen.

La falta de relaciones significativas entre estas variables no es un resultado definitivo en la medida que se requieren otros estudios con mayor número de sujetos, y con mayor variedad de indicadores para cada variable, ya que se han utilizado promedios de las propiedades estructurales en las redes sociales personales, así como indicadores subjetivos de Calidad de Vida en Salud. Esto indica que es un primer acercamiento a las redes sociales personales en contexto de desplazamiento por violencia política en la Costa Atlántica. 
La falta de relaciones entre estas dos variables también da cuenta del sutil equilibrio que implica la red y el apoyo social con otros indicadores de salud ya que se han identificado algunos efectos paradójicos mencionados por Leavy (1983, citado por Tousignant 1992), en relación con los estilos de personalidad y la manera de percibir el apoyo brindado por el medio, al igual que por las propiedades de independencia entre los indicadores de apoyo recibido y salud mental, ya que estos indicadores harían parte de factores psicométricos diferentes (Tousignant, 1992).

Sin embargo es posible observar las relaciones que sin ser significativas, son interesantes de resaltar. Al observar en los grafos la calidad de vida de cada uno de los Egos (Ver Figuras 3 y 4), se ve que sólo uno de ellos - en el grupo de los que Llegan - presenta un nivel moderado. Este grupo también presenta los niveles más altos de calidad de vida, así sean bajos en la mayoría de sus integrantes. Estos datos apoyan la hipótesis que las personas que llegan (con menos de tres meses) tienen mejores indicadores de calidad de vida que aquellos que han pasado más de un año en el lugar de refugio. Esto puede deberse a los cambios en la relación del apoyo social (una de las funciones de la red social) y el sentimiento de control sobre la vida. Se ha observado en contextos de gran pobreza que los contactos entre amigos son menos frecuentes y se presentan menos relaciones de apoyo significativas, lo cual aumenta los niveles de depresión en las mujeres (Brown y Harris, 1978). Además, en una investigación de Turner y Noh (1980, citado por Thoits, 1982), se observó que las madres jóvenes de los sectores pobres que reciben un alto apoyo social y además tienen el sentimiento de controlar sus vidas, presentan un nivel de salud mental promedio equivalente al de mujeres de otros contextos sociales, lo cual deberá ser confirmado por otros estudios en la población desplazada.

\section{Discusión}

Esta investigación trataba de responder dos preguntas. La primera buscaba determinar la diferencia entre los indicadores de redes sociales personales y la calidad de vida en salud entre los grupos de desplazados de acuerdo al tiempo de vivir en el asentamiento. Se esperaba encontrar diferencias significativas entre ambos, en particular a favor del grupo que Llega. Los resultados prueban de manera parcial esta hipótesis, ya que sólo la calidad de vida, en su dimensión de salud física es percibida significativamente más deteriorada por los desplazados que llevan más de un año en el asentamiento (Asentados), con respecto a los que tienen menos de tres meses (Llegan). Esto sugiere que el tiempo pasado en el 
asentamiento afecta la salud de los desplazados, lo cual es consistente con los resultados de Palacio y Sabatier (2002).

La segunda pregunta buscaba establecer la relación entre los indicadores de redes sociales personales de los desplazados y sus indicadores de calidad de vida en salud. Se esperaba encontrar una respuesta que mostrara al menos que los altos niveles de densidad se relacionarían con bajos niveles de calidad de vida. En este aspecto los resultados mostraron que no existían correlaciones significativas entre estas variables. De esta manera, la red social personal - sus indicadores cuantitativos - (densidad, centralidad, cercanía), no tienen una relación significativa con las condiciones de vida objetivas y la satisfacción subjetiva en las dimensiones de la salud física y mental de los desplazados que participaron en el estudio.

Si bien los resultados no son concluyentes, en parte por las características propias de la metodología del estudio - las cuales a su vez deben tener en cuenta las condiciones del terreno - sí arrojan algunas luces sobre la dinámica de las redes sociales y la calidad de vida de las personas en estos contextos difíciles, en los cuales los desplazados además de enfrentar la pobreza deben cargar a cuestas con un pasado que puede ser para la mayoría traumático, y además tratar de ver con optimismo el futuro en medio de una red de familiares y amigos que están padeciendo consecuencias similares, y que por lo tanto no son la mejor ayuda que les permitirá establecer puentes para acceder a informaciones útiles sobre recursos de diferente índole.

Como se indicó anteriormente, las dificultades en la construcción de comunidad tienen su origen - entre otros factores - en la desconfianza que existe entre las personas desplazadas y no desplazadas, así como los conflictos que se generan al interior de ambos grupos por la administración de los recursos que reciben (Palacio y Sabatier, 2002). Estos resultados están mostrando lo encapsulados que están en su comunidad y la necesidad de establecer puentes que les permitan entrar en contactos con otros recursos aún poco accesibles, sin embargo la desconfianza que se ha tejido y alimentado entre los habitantes bloquea este tipo de intercambios. No hay duda que esto dificulta el establecimiento y fortalecimiento de las redes de apoyo que son un factor clave para lograr comunicarse adecuadamente con la comunidad receptora (Martínez, García, Maya, 2001; King, L, King, D, Fairbank, Keane y Adams, 1998). Es un problema mayor en la medida que el establecimiento de una red interpersonal es uno de los más críticos y difíciles problemas que enfrenta una persona desplazada o inmigrante que acaba de llegar, conjuntamente con la búsqueda de alimento y refugio. Además, las características de la red de 
apoyo tendrán una influencia fundamental en el desarrollo de su habilidad para comunicarse con la sociedad receptora, así sean de la misma nacionalidad y hablen la misma lengua. En sí, las estrategias de integración aun no están funcionando adecuadamente ya que sólo están cumpliendo con su papel básico de apoyo a la supervivencia, pero es necesario que pasen a su rol principal en el apoyo a la construcción de comunidad.

Esto será un paso que deberá ser fomentado por los organismos de apoyo social (Gobierno y Ong's), en la medida que se hace visible y persiste en el tiempo el recurso a los lazos fuertes (familia y amigos), que brindan sobre todo apoyo afectivo, pero aún en este caso es necesario cuestionarse qué tan efectivo está siendo para preservar la salud y calidad de vida de los desplazados. En general se considera que el recurrir a los lazos fuertes sería una respuesta de los pobres e inseguros a la presión de la carencia económica, y por medio del vínculo familiar y de sangre, unido a la reciprocidad se facilitaría la adaptación a los contextos hostiles. El problema señalado por Granovetter (2003), es que la fuerte concentración en estos lazos tiende a construir redes encapsuladas con pocas conexiones o puentes entre sí, lo cual es un factor adicional para que la pobreza se perpetúe.

Aquí se entiende que las dinámicas de aglomeración o encapsulamiento de los desplazados o los pobres que viven en determinados sectores de la periferia de las ciudades pueden obedecer a la necesidad de reducir el sentimiento de inseguridad o vulnerabilidad al buscar incorporarse a una comunidad de desplazados de la misma región para apoyarse por lazos de familiaridad en la búsqueda de trabajo o de diferentes recursos para la supervivencia. Blau (1974, citado por Granovetter, 2003), también explica este tipo de aglomeración por la homofilia (tendencia a elegir como amigos a aquellos que son similares a nosotros), donde la presencia de otros desplazados del mismo lugar ayuda a adaptarse al nuevo contexto y estará muy relacionada con la habilidad del sujeto para explotar las fuentes de soporte social, lo cual le permitirá integrarse mejor y preservar su bienestar psicológico. La efectividad de estas aglomeraciones se han observado, por ejemplo, en redes de inmigrantes donde se encontró que la integración a redes familiares o de amigos se relaciona con niveles más bajos de depresión, mejor estado de ánimo, mejor percepción de salud física y autonomía funcional, así como mayor satisfacción con la vida y bienestar general (Maya, 2002). 
Sin embargo este agrupamiento puede también disminuir las posibilidades de establecer puentes con otras redes que brindarían mayores oportunidades para mejorar las condiciones económicas de la comunidad. Este efecto perverso - que se refleja en esta comunidad de desplazados - es particularmente visible cuando el agrupamiento obedece más a decisiones de gobiernos locales tomadas en la urgencia. Es decir que las autoridades locales los asignan a un lugar particular sin prever una planeación adecuada para su integración (vías de acceso, seguridad, servicios sanitarios básicos, etc.), con el riesgo de crear ghetos aislados, en los cuales podemos indicar la existencia de una segregación geográfica (Rhein, 1988). Esto favorece que se auto identifiquen como grupo de desplazados, que se vean más como víctimas 9 y tengan un estatus minoritario en la población que los recibe, quien a su vez los identifica como tales. Por otro lado, a pesar de tener una misma nacionalidad, las características culturales de cada individuo con respecto a su región hacen que se presenten roces de diferente índole que refuerzan los estereotipos - particularmente negativos - previamente existentes en cada uno de los grupos.

De aquí surgen una serie de cuestionamientos sobre el modelo de red y apoyo social en situaciones de desplazamiento entre los que se pueden mencionar algunos de los siguientes: ¿Las redes y el apoyo social en los desplazados internos siguen un patrón de acción similar al que se presenta en los grupos de inmigrantes? Al respecto sería interesante ver las convergencias en las tipologías de las redes tal como se ha sugerido en otras investigaciones (Maya, 2002; Maya y Vega, 2004). ¿Se puede hacer evidente la relación entre los indicadores de "redes" con los indicadores de "salud"? ¿Los cambios en la salud de los desplazados se pueden deber entre otros factores, a las características propias de su red de apoyo actual o a problemas existentes antes del desplazamiento? ¿Se puede diferenciar el efecto de la densidad y la calidad de las relaciones en la salud de las personas desplazadas? Para tratar de encontrar una respuesta adecuada a cada uno de ellos se requieren diferentes estrategias metodológicas que implican estudios con grados de dificultad diversos, los cuales se abordarán en la medida que el acceso a la comunidad sea seguro.

9 Favoreciendo comportamientos asistencialistas y disminuyendo la autogestión necesaria para la reconstrucción de sus proyectos de vida. 


\section{Conclusiones}

Se encontró evidencia parcial para responder a la pregunta que buscaba determinar la diferencia entre los indicadores de redes sociales personales y la calidad de vida en salud entre los grupos de desplazados de acuerdo al tiempo de vivir en el asentamiento. Sólo la calidad de vida, en su dimensión de salud física, es percibida significativamente peor en los desplazados que llevan más de un año en el asentamiento (Asentados), con respecto a los que tienen menos de tres meses (Llegan). Además, tampoco se encontraron correlaciones significativas entre los indicadores de redes sociales personales de los desplazados y sus indicadores de calidad de vida en salud.

Los Indicadores de Calidad de Vida (Salud Física y Mental) por sí solos presentan las condiciones de vida difíciles que experimenta esta población. Los promedios en las subescalas están entre 31 y 55 puntos, mientras que se esperaría al menos un promedio de 77 puntos tal como lo registra la población española (Iraurgi, Póo, Màrkez, 2004). El tiempo de llegada afecta en parte esta variable, lo cual confirma los resultados del estudio de Palacio y Sabatier (2002).

La estructura de las redes sociales personales de los desplazados se entiende desde la teoría de los lazos débiles de Granovetter (2003), se caracteriza por presentar lazos fuertes, donde los nodos son principalmente transmisores con relaciones mutuas, y se presentan altos niveles de cohesión por un contacto diario entre los miembros. Este contacto es asegurado en su mayoría por miembros de la familia próxima que viven en la misma casa del Ego o en sus inmediaciones cercanas, de allí que el tipo de recursos solicitados a esta red son de todo tipo (afectivos, económicos, informativos, de recreación, de socialización, etc.), y su grado de reciprocidad es elevado. La falta de lazos débiles no permite el acceso a mayores recursos en otros ámbitos de la vida social, y es la desconfianza una de las causas de este encapsulamiento.

Este tipo de contacto no es muy satisfactorio en la medida que sólo será posible construir comunidad y generar un mayor bienestar social si estos temores y desconfianza se reducen y dan paso a comportamientos de cooperación y apoyo recíproco. De aquí que la observación y refuerzo de las redes sociales personales entre ambas comunidades (desplazadas y receptoras) es una manera de apoyar el incremento del bienestar en comunidades donde el capital social está aún opacado por el desconocimiento del otro. 


\section{Bibliografía}

Araya, Rodrigo., Maya, Isidro. (2005). "Los puentes interlocales: las redes personales de los universitarios alcalareños en Sevilla". Investigacion presentada en el III Seminario para el Análisis de Redes Sociales en Sevilla - España. I International Workshop ( 7, 8 y 9 de Septiembre). Coordinadores I sidro Maya, Jose Luis Molina y Estrella Gualda.

Barrera, M., Sandler, I.N. \& Ramsay, T.B. (1981). "Preliminary development of a scale of social support: Studies on college students". American Journal of Community Psychology, 9, 435-447.

Blau, P.M. (1974). "Parameters of social structure". American Sociological Review, 39, 615-635.

Borgatti, S.P., M.G. Everett, and L.C. Freeman. (2002). UCINET 6 for Windows: Software for Social Network Análisis. Version 6.101. Harvard: Analytic Technologies.

Borthwick-Duffy, S.A. (1992). "Quality of life and quality of care in mental retardation". In L. Rowitz (Ed.), Mental retardation in the year 2000 (pp.52-66). Berlin: Springer-Verlag.

Brown, G. \& Harris, T. (1978). The Social Origins of Depression : A Study of Psychiatric Disorders among Women. Londres : Tavistock.

Castaño, B. (1994). Violencia sociopolítica en Colombia - Repercusiones en la salud mental de las víctimas. Santa fe de Bogotá: Editorial Gente Nueva.

CODHES. (1997). “Desplazados 1997: Éxodos, miedo y pobreza". Bajado en diciembre de 2005: http://www.codhes.org.co/

CODHES. (2004). "Conflicto armado y crisis humanitaria sostenida. Desplazados en el Limbo". Boletín de prensa- Bogotá, 1 de febrero de 2004. Bajado en Julio 2004 de: http://www.actualidadcolombia.org/archivo/despalaz/2005/12.rtf.

Eurelings-Bontekoe, E., Diekstra, W. \& Verschuur, M. (1995). “Psychological distress, social support and social support seeking: A prospective study among primary mental health care patients". Social Sciences Medicine, Vol. 40, $\mathrm{N}^{\circ} 8$, 1083-1089.

Felce, D. y Perry, J. (1995). "Quality of life: It's Definition and Measurement". Research in Developmental Disabilities, Vol. 16, № 1, pp. 51-74.

Gómez-Vela, María; Sabeh, Eliana. (2005). “Calidad de vida. Evolución del concepto y su influencia en la investigación y la práctica". Facultad de Psicología, Universidad de Salamanca. Bajado en junio 2005 de: http://campus. usal. es/ inico/investigación/invesinico/calidad.htm.

Granovetter, M. (2003). “La fuerza de los lazos débiles. Revisión de la teoría reticular". En: Requena (2003).

Granovetter, M. (1973). "The strength of weak ties". American Journal of Sociology, 78. 1360-1380. 
Iraurgi, Póo, Màrkez. (2004). "Valoración del indice de salud SF-36 aplicado a usuarios de programas de metadona. Valores de referencia para la Comunidad Autonoma Vasca". Rev. Esp. Salud Pública: 78. No.5, 609-621.

King, L., King, D., Fairbank, J., Keane, T. \& Adams, G. (1998). "Resilience-recovery factors in Post-traumatic stress disorder among female and male vietnam veterans: hardiness, post-war social support, and additional stressful life events". Journal of Personality and Social Psychology, Vol. 74, $\mathrm{N}^{\circ} 2,420-434$.

Macksoud, M., Aber, L., Dyregrov, A. \& Raundalen, M. (1990). Child Behavior Inventory. New York: Columbia University, Center for the Study of Human Rights, Projet on Children and War.

Madariaga, C., Martínez, R. \& Vides, M. (1993). Redes sociales de las madres comunitarias del barrio Villa del Carmen. Tesis de Psicología, Universidad del Norte, Barranquilla, Colombia.

Martínez, M., García, M. \& Maya, I. (2001). “Una Topología analítica de las redes de apoyo social de los inmigrantes africanos en Andalucía". Universidad de Sevilla. Revista Española de Investigaciones Sociológicas, № 95, 99-125.

Marie Stopes Internacional (2003). “Desplazados y Desesperados: Evaluación sobre la Salud Reproductiva en la Población Desplazada en Colombia". Women's Commission for Refugee Women and Children, en nombre de Reproductive Health Response in Conflict Consortium. Bajado en Marzo 2004 de: http://www.rhrc.org

Maya Jariego, I. (2002). "Tipos de redes personales de los inmigrantes y adaptación psicológica". Redes. Revista hispana para el análisis de redes sociales. Vol. 1\#4, pp.1-56. http://revista-redes.rediris.es

Maya Jariego, I. (2004). "Sentido de comunidad y potenciación comunitaria" Apuntes de Psicología. Vol.22, número 2, págs.187-211.

Maya, Jariego y Vega, L. de la (2004). "Niveles de multiplicidad y tipos de proveedores de apoyo: las redes personales de los inmigrantes indios en Argentina". IV Mesa Hispana para el análisis de las redes sociales. XXIV International Sunbelt Social Network Conference. Portoroz, Slovenia, 12-16 de mayo, pp. 1-21.

McHorney CA, Ware JE, Lu JFR, Sherbourne CD. (1994). "The MOS 36-Item ShortForm Health Survey (SF-36): III. Tests of data quality. Scaling assumptions, and reliability across diverse patient groups". Med Care; 32: 40-66.

Osorio, F y Lozano, F. (1995). “Desplazamiento rural: violencia y pobres". Bogotá, Consultoría para los Derechos Humanos y el Desplazamiento (CODHES). Bogotá.

Palacio, J., Abello, R., Madariaga, C. \& Sabatier, C. (1999). “Estrés postraumático y resistencia psicológica en jóvenes desplazados". Investigación y Desarrollo, N 10.

Palacio, J., Sabatier, C., (2002). Impacto psicológico de la violencia política en Colombia. Ediciones Uninorte, Barranquilla.

PMA (2003). "Desplazados en riesgo. Programa Mundial de Alimentos". BBC Mundo.com. Bajado en junio de 2003 de: http://news8.thdo.bbc.co.uk/hi/spanish/latin_america/newsid_3006000/3006422.s tm 
Red de Solidaridad Social. (2005). Informe sobre Desplazamiento Forzado en Colombia. Primer trimestre - Unidad técnica conjunta. Bogotá.

Rhein, C. (1988). “La ségrégation démographique". In M. Bonvalet (Ed.), Transformations de la famille et de l'habitat. Paris: INED, "Travaux et Documents", Cahier 120.

Requena, Félix (2003). Análisis de Redes Sociales. Orígenes, teorías y aplicaciones. Colección Monografías. Número 198. Centro de investigaciones Sociológicas, Siglo XX. Madrid.

Rueda, R. (1997). Desplazados por la violencia en Colombia : entre el miedo... la soledad... y la esperanza. Universidad Nacional de Colombia: Medellín.

Salazar, A. (1995). El silencio de los desplazados en Bogota. Bogota: Comisión Arquidiocesana de Pastoral de la Movilidad Humana.

SPSS (2002). Statistical Package for Social Sciences. Version 11.0.1. para Windows. Leadtools. Inc.

Thoits P.M. (1982). "Life stress, social support, and psychological vulnerability: epidemiological considerations", J ournal of Community Psichology, 10, pp.341-362.

Tousignant, M. (1992). Les origines sociales et culturelles des troubles psychologiques. Paris: PUF.

Vega, W., Kolody, B., Valle, R. \& Weir, J. (1991). "Social networks, social support and their relationship to depression among Mexican immigrant women". Human Organisation, Vol. 50(2), 154-162. 
REDES- Revista hispana para el análisis de redes sociales Vol. 9,\#3, Diciembre 2005.

http: // revista-redes.rediris.es

\section{ANEXOS}

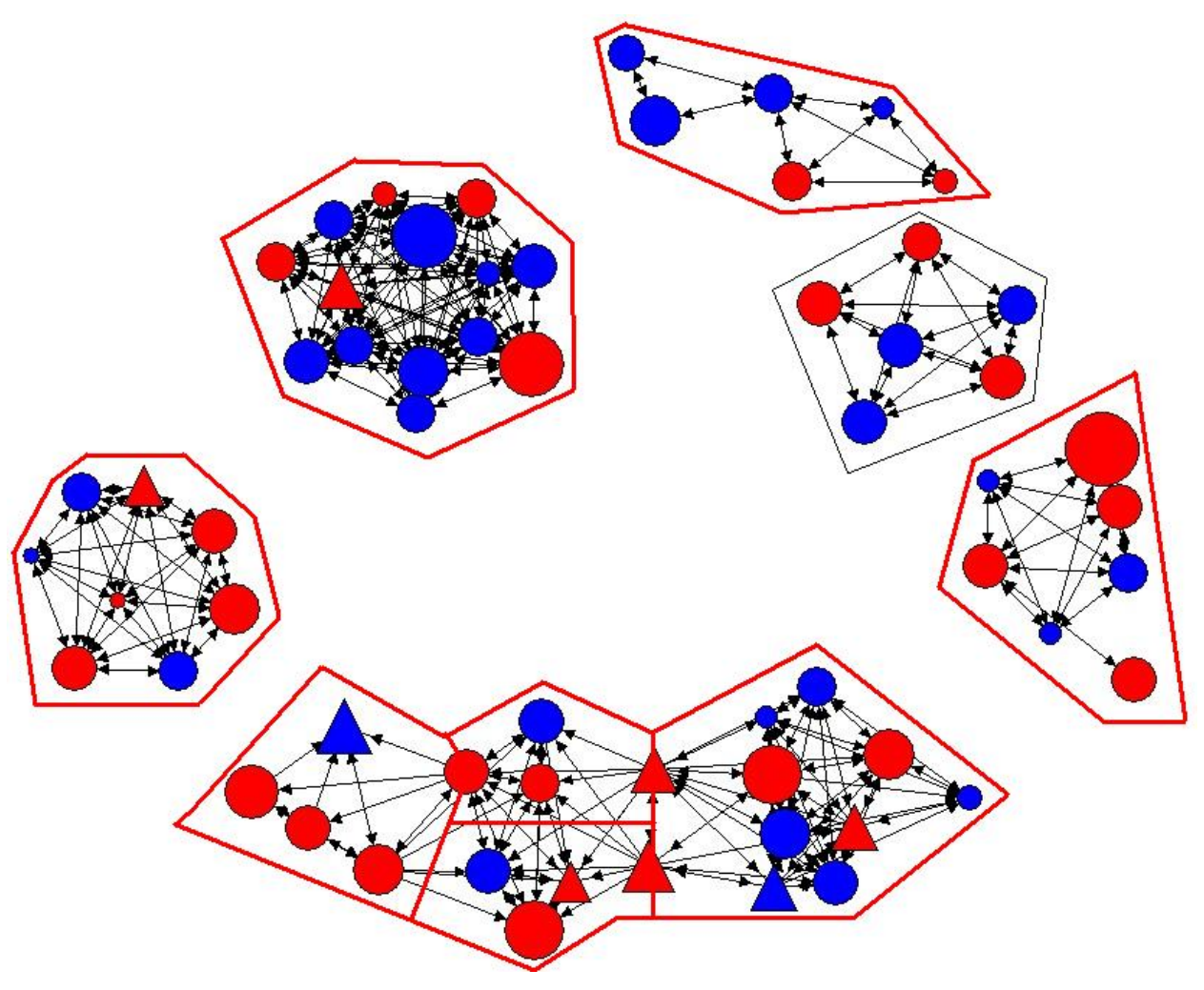

Color de Nodos: Sexo (masculino - azul, femenino - rojo).

Forma de Nodos: Vínculo fuerte: círculo - familiares o amigos.

Vínculo débil: triángulo - conocidos, vecinos u otros.

Tamaño de nodos: Cantidad de apoyo.

Calidad de Vida del EGO: Muy Baja

Baja

Moderada

Figura 3. Grafos Personales y Calidad de Vida en los Asentados 


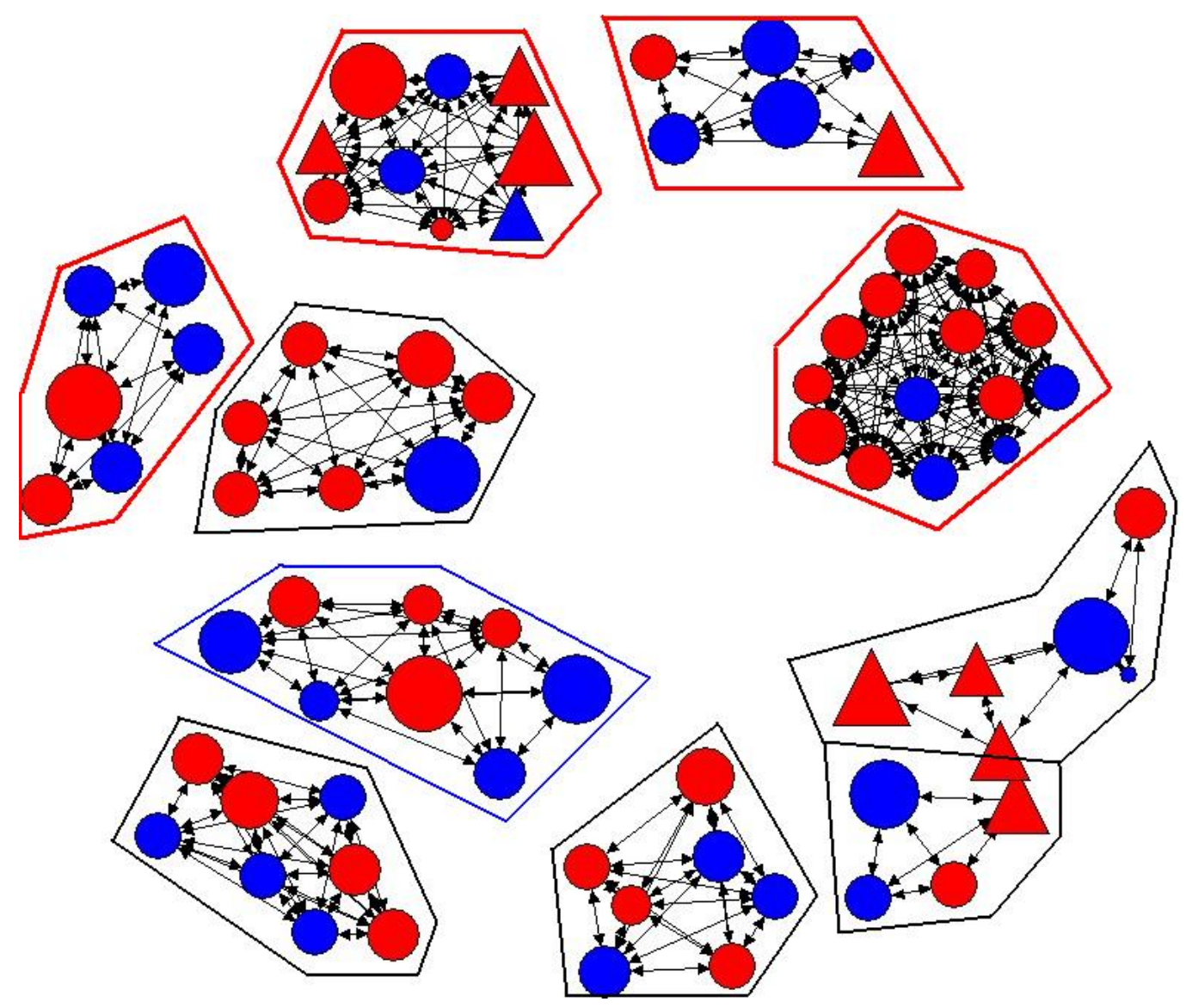

Color de Nodos: Sexo (masculino - azul, femenino - rojo).

Forma de Nodos: Vínculo fuerte: círculo - familiares o amigos.

Vínculo débil: triángulo - conocidos, vecinos u otros.

Tamaño de nodos: Cantidad de apoyo.

Calidad de Vida del EGO: Muy Baja

Baja

Moderada

Figura 4. Grafos Personales y Calidad de Vida en los que Llegan 
REDES- Revista hispana para el análisis de redes sociales

Vol.9,\#3, Diciembre 2005.

http://revista-redes. rediris. es

Tabla 4. Correlaciones Grupo que Llega

\begin{tabular}{|c|c|c|c|c|c|c|c|c|c|c|c|c|c|c|c|c|}
\hline & $\begin{array}{l}\text { Centralidad } \\
\text { Salida } \\
\text { Normalizad } \\
\text { o } \\
\end{array}$ & $\begin{array}{l}\text { Centralidad } \\
\text { promedio }\end{array}$ & $\begin{array}{l}\text { Centraliza } \\
\text { ción OutD } \\
\%\end{array}$ & $\begin{array}{l}\text { Centraliza } \\
\text { ción InD } \\
\%\end{array}$ & $\begin{array}{l}\text { Intermedi } \\
\text { ación } \\
\text { promedio }\end{array}$ & $\begin{array}{l}\text { Cercanía } \\
\text { promedio } \\
\%\end{array}$ & $\begin{array}{l}\text { Funcio } \\
\text { namien } \\
\text { to físico }\end{array}$ & $\begin{array}{l}\text { Rol } \\
\text { físico }\end{array}$ & $\begin{array}{l}\text { Enferm } \\
\text { edad } \\
\text { corpora } \\
\\
\end{array}$ & $\begin{array}{l}\text { Salud } \\
\text { general }\end{array}$ & $\begin{array}{l}\text { Vitalida } \\
\text { d }\end{array}$ & $\begin{array}{l}\text { Función } \\
\text { social }\end{array}$ & $\begin{array}{l}\text { Rol } \\
\text { emociona } \\
\text { I }\end{array}$ & $\begin{array}{l}\text { Salud } \\
\text { mental }\end{array}$ & $\begin{array}{l}\text { Salud } \\
\text { Física } \\
\text { General }\end{array}$ & $\begin{array}{l}\text { Salud } \\
\text { Mental } \\
\text { General }\end{array}$ \\
\hline $\begin{array}{l}\text { Densidad } \\
\text { promedio }\end{array}$ &, 500 & $1,000\left({ }^{\star *}\right)$ &,$- 695\left({ }^{*}\right)$ &,$- 635(*)$ &,$- 700(*)$ &, $725\left(^{*}\right)$ &,- 043 & ,291 & ,025 &,- 370 &,- 535 & ,012 & ,227 & ,357 &,- 017 & ,087 \\
\hline $\begin{array}{l}\text { Centralidad } \\
\text { Salida } \\
\text { Normalizad } \\
\text { o } \\
\end{array}$ & & 499 & ,233 & ,276 & 107 & -,116 & ,029 & 204 & 100 &,- 204 &,- 555 &,- 136 &,- 110 & ,135 & ,059 &,- 364 \\
\hline $\begin{array}{l}\text { Centralidad } \\
\text { promedio }\end{array}$ & & &,$- 696\left(^{*}\right)$ &,$- 637\left(^{*}\right)$ &,$- 703\left({ }^{*}\right)$ &, $728\left(^{*}\right)$ &,- 045 & ,287 & ,023 &,- 367 &,- 536 &, 007 & ,223 &, 360 &,- 019 & ,083 \\
\hline $\begin{array}{l}\text { Centralizaci } \\
\text { ón OutD \% }\end{array}$ & & & &, $971(\star *)$ &, $852\left({ }^{* *}\right)$ &,$- 877(* *)$ &, 088 & 年, &,- 083 & ,279 & ,083 &,- 097 &,- 344 &,- 233 &, 047 &,- 368 \\
\hline $\begin{array}{l}\text { Centralizaci } \\
\text { ón InD \% }\end{array}$ & & & & &, $819(\star \star)$ &,$- 840(* \star)$ &, 272 &,- 042 & ,034 & ,297 & ,178 &, 043 &,- 229 &,- 339 & , 236 &,- 233 \\
\hline $\begin{array}{l}\text { Intermediac } \\
\text { ión } \\
\text { promedio }\end{array}$ & & & & & &,$- 986(* \star)$ &,- 027 & - 136 &,- 065 & - -044 & 135 & , 027 & - 169 &,- 256 &,- 076 & -178 \\
\hline $\begin{array}{l}\text { Cercanía } \\
\text { promedio } \\
\%\end{array}$ & & & & & & & ,000 & 124 & 076 & ,006 & -,182 &,- 053 & 190 & ,305 & , 051 & 178 \\
\hline $\begin{array}{l}\text { Funcionami } \\
\text { ento físico }\end{array}$ & & & & & & & & ,407 & ,324 & ,156 & ,627 & ,629 &, 365 &,- 616 & ,888(**) &, 540 \\
\hline Rol físico & & & & & & & & &, $675\left(^{*}\right)$ & ,012 & , 260 &, $810\left({ }^{(*)}\right)$ & ,876(**) &,$- 668\left(^{*}\right)$ &, $694\left({ }^{*}\right)$ &, $\left.6800^{*}\right)$ \\
\hline $\begin{array}{l}\text { Enfermeda } \\
\text { d corporal }\end{array}$ & & & & & & & & & & , 180 &, 350 & ,359 &, 584 &,- 555 &, $665\left(^{\star}\right)$ & ,334 \\
\hline $\begin{array}{l}\text { Salud } \\
\text { general }\end{array}$ & & & & & & & & & & & ,434 &,- 054 &,- 267 &,- 410 & ,334 &,- 234 \\
\hline Vitalidad & & & & & & & & & & & & ,584 & ,280 & $\begin{array}{ll}-814\left(^{\star *}\right) \\
\end{array}$ & ,655(*) &, 525 \\
\hline $\begin{array}{l}\text { Función } \\
\text { social }\end{array}$ & & & & & & & & & & & & & ,830(**) &,$- 772\left(^{(*)}\right.$ &, $709\left(^{*}\right)$ &, $904(* *)$ \\
\hline $\begin{array}{l}\text { Rol } \\
\text { emocional }\end{array}$ & & & & & & & & & & & & & &,- 512 &, 562 &, $882(* \star)$ \\
\hline $\begin{array}{l}\text { Salud } \\
\text { mental }\end{array}$ & & & & & & & & & & & & & & &,$\left.- 796{ }^{* \star}\right)$ &,- 536 \\
\hline $\begin{array}{l}\text { Salud } \\
\text { Física } \\
\text { General }\end{array}$ & & & & & & & & & & & & & & & & ,576 \\
\hline
\end{tabular}

** La correlación es significativa a 0.01 (bilateral).
* La correlación es significativa a 0.05 (bilateral). 
Tabla 5. Correlaciones Grupo Asentados

\begin{tabular}{|c|c|c|c|c|c|c|c|c|c|c|c|c|c|c|c|c|}
\hline & $\begin{array}{l}\text { Centralidad } \\
\text { Salida } \\
\text { Normalizad } \\
\text { o }\end{array}$ & $\begin{array}{l}\text { Centralidad } \\
\text { promedio }\end{array}$ & $\begin{array}{l}\text { Centraliz } \\
\text { ación } \\
\text { OutD \% }\end{array}$ & $\begin{array}{l}\text { Centraliz } \\
\text { ación InD } \\
\%\end{array}$ & $\begin{array}{l}\text { Intermed } \\
\text { iación } \\
\text { promedio }\end{array}$ & $\begin{array}{l}\text { Cercanía } \\
\text { promedio } \\
\%\end{array}$ & $\begin{array}{l}\text { Funcio } \\
\text { namien } \\
\text { to } \\
\text { físico }\end{array}$ & $\begin{array}{l}\text { Rol } \\
\text { físico }\end{array}$ & $\begin{array}{l}\text { Enfermed } \\
\text { ad } \\
\text { corporal }\end{array}$ & $\begin{array}{l}\text { Salud } \\
\text { general }\end{array}$ & $\begin{array}{l}\text { Vitalida } \\
\text { d }\end{array}$ & $\begin{array}{l}\text { Función } \\
\text { social }\end{array}$ & $\begin{array}{l}\text { Rol } \\
\text { emociona } \\
\text { I }\end{array}$ & $\begin{array}{l}\text { Salud } \\
\text { mental }\end{array}$ & $\begin{array}{l}\text { Salud } \\
\text { Física } \\
\text { General }\end{array}$ & $\begin{array}{l}\text { Salud } \\
\text { Mental } \\
\text { General }\end{array}$ \\
\hline $\begin{array}{l}\text { Densidad } \\
\text { promedio }\end{array}$ &, $725(*)$ &, $993(* *)$ &,- 455 &,- 555 &,- 630 &, $820(* *)$ &,- 027 &, 219 &,- 069 &, 058 &,- 021 & , 198 &,- 460 & , 161 &, 001 &,- 039 \\
\hline $\begin{array}{l}\text { Centralidad } \\
\text { Salida } \\
\text { Normalizad } \\
\text { o } \\
\end{array}$ & &, $731(*)$ & ,268 &, 122 & ,014 & , 272 &,- 058 & ,226 &,- 202 & ,395 & ,209 & ,299 &,- 541 &,- 290 & 104 &,- 035 \\
\hline $\begin{array}{l}\text { Centralidad } \\
\text { promedio }\end{array}$ & & &,- 459 &,- 560 &,- 637 &, $818(* *)$ &,- 021 & , 199 &,- 046 &, 085 &, 019 & ,269 &,- 480 & ,204 &, 026 &, 052 \\
\hline $\begin{array}{l}\text { Centralizac } \\
\text { ión OutD } \\
\%\end{array}$ & & & &, $958(* *)$ &, $928(* *)$ &, $800(* *)$ &,- 041 & .038 &,- 151 & ,387 & ,226 &,- 002 &,- 052 &,- 655 & 114 &,- 152 \\
\hline $\begin{array}{l}\text { Centralizac } \\
\text { ión InD \% }\end{array}$ & & & & &, $924(* *)$ & $\begin{array}{r}.807(* *) \\
\end{array}$ & , 141 & , 201 & .043 & ,453 & ,128 &, 120 &,- 018 &,- 656 & ,311 &,- 052 \\
\hline $\begin{array}{l}\text { Intermedia } \\
\text { ción } \\
\text { promedio }\end{array}$ & & & & & &, $935(* *)$ & ,095 &, 215 &,- 058 & 120 & 116 &,- 078 &,- 127 &,- 472 & ,080 &,- 262 \\
\hline $\begin{array}{l}\text { Cercanía } \\
\text { promedio } \\
\%\end{array}$ & & & & & & &,- 017 & 120 & , 159 & ,043 &,- 181 & , 184 &,- 088 &, 363 & ,077 & 171 \\
\hline $\begin{array}{l}\text { Funcionami } \\
\text { ento físico }\end{array}$ & & & & & & & & ,548 & .467 & ,208 &,- 396 &, $695\left(^{*}\right)$ &,- 489 &, 064 &, $808(* *)$ & ,242 \\
\hline Rol físico & & & & & & & & &,$- 893(* *)$ &,- 057 &, 354 &,- 341 &, 472 &,- 316 &,- 609 &, 000 \\
\hline $\begin{array}{l}\text { Enfermeda } \\
\text { d corporal }\end{array}$ & & & & & & & & & & ,151 &,- 521 &, 423 &,- 286 & ,393 &, 657 & , 147 \\
\hline $\begin{array}{l}\text { Salud } \\
\text { general }\end{array}$ & & & & & & & & & & &, 282 &, 598 &, 083 &,- 632 &, $672(*)$ &, 569 \\
\hline Vitalidad & & & & & & & & & & & & - & ,121 & - &,- 253 &, 335 \\
\hline $\begin{array}{l}\text { Función } \\
\text { social }\end{array}$ & & & & & & & & & & & & &,- 413 & ,033 &, $828(* *)$ &, $746(*)$ \\
\hline $\begin{array}{l}\text { Rol } \\
\text { emocional }\end{array}$ & & & & & & & & & & & & & &,- 271 &,- 312 & , 163 \\
\hline $\begin{array}{l}\text { Salud } \\
\text { mental }\end{array}$ & & & & & & & & & & & & & & &,- 154 &, 000 \\
\hline $\begin{array}{l}\text { Salud } \\
\text { Física } \\
\text { General } \\
\end{array}$ & & & & & & & & & & & & & & & & ,476 \\
\hline
\end{tabular}

** La correlación es significativa a 0.01 (bilateral).

* La correlación es significativa a 0.05 (bilateral). 